\title{
Market mechanisms for newborn health in Nepal
}

\author{
Karsten Lunze ${ }^{1,2^{*}} \mathbb{D}$, Rosie Dawkins ${ }^{1}$, Abeezer Tapia ${ }^{3}$, Sidharth Anand ${ }^{3}$, Michael Chu $^{3}$ and David E. Bloom ${ }^{1}$
}

\begin{abstract}
Background: In Nepal, hypothermia is a major risk factor for newborn survival, but the country's public health care sector has insufficient capacity to improve newborn survival given the burden imposed by distance to health facilities and cost. Low-cost technology to provide newborn thermal care in resource-limited environments exists, but lacks effective distribution channels.

This study aims to develop a private sector distribution model for dedicated newborn thermal care technology to ensure equitable access to thermal protection and ultimately improve newborn health in Nepal.

Methods: We conducted a document analysis of newborn health policy in Nepal and a scoping literature review of approaches to newborn hypothermia in the region, followed by qualitative interviews with key stakeholders of newborn health in Nepal.

Results: Current solutions addressing newborn hypothermia range from high-technology, high-cost incubators to lowcost behavioral interventions such as skin-to-skin care. However, none of these interventions are currently implemented at scale. A distribution model that provides incentives for community health volunteers and existing public health services in Nepal can deliver existing low-cost infant warmers to disadvantaged mothers where and when needed. Newborn technology can serve as an adjunct to skin-to-skin care and potentially create demand for newborn care practices.

Conclusion: Harnessing market forces could promote public health by raising awareness of newborn challenges, such as newborn hypothermia, and triggering demand for appropriate health technology and related health promotion behaviors. Market approaches to promoting public health have been somewhat neglected, especially in economically disadvantaged and vulnerable populations, and deserve greater attention in Nepal and other settings with limited public health service delivery capacity.
\end{abstract}

Keywords: Health technology, Social entrepreneurism, Incentive, Newborn, Hypothermia, Nepal

\section{Background}

Despite significant efforts for children under 5 years of age, newborn survival has progressed insufficiently in Nepal. Although the country's current newborn mortality rate decreased compared with 59/1000 live births in 1990, it remained stagnant at 33/1000 in 2006 and 2011 according to the Nepal Demographic and Health Surveys (DHS) [1]. Over the past two decades, the proportion of newborn deaths in Nepal contributing to overall child mortality even increased from 24 to $61 \%$ of all deaths in children under 5 years of age $[2,3]$. Each year, more than 4700

\footnotetext{
* Correspondence: karsten.lunze@post.harvard.edu

'Department of Global Health and Population, Harvard T.H. Chan School of Public Health, 677 Huntington Avenue, Boston, MA 02115, USA

${ }^{2}$ Boston Medical Center, 801 Massachusetts Avenue, Boston, MA 02118, USA

Full list of author information is available at the end of the article
}

newborns die in Nepal on their first day of life, and 13,000 die in their first 28 days of life [4], mostly due to problems related to prematurity ( $27 \%$ of newborn mortality), birth asphyxia (29\%), or severe infections (24\%) [3].

Newborn hypothermia, defined as an abnormally low body temperature below $36.5{ }^{\circ} \mathrm{C}$ [5], is an important contributor to these causes of death, particularly in high-risk environments such as Nepal [6]. It is associated with a significantly increased mortality risk [7], particularly in premature or low-birth-weight infants [8], half of whom globally are born in South Asia [9]. Newborn hypothermia is highly prevalent in Nepal: Even in institutions with skilled birth attendants, recorded prevalences range between 63 and $85 \%$ [10-13]. The most recent data from a communitybased study in Nepal indicate that hypothermia is nearly 
universal [14]. While hypothermia risk is higher in the cold season, incidence in the hot season is also high [14]. Given a newborn's physiological vulnerability to hypothermia, year-round thermal protection is required, even in warmer environments [6].

For thermoprotection of newborns, the World Health Organization (WHO) recommends a "warm chain" of heating the delivery room, immediate drying, providing skin-to-skin care, early and exclusive breastfeeding, postponing bathing, providing appropriate clothing and bedding, and placing mother and baby together [15]. However, implementing effective interventions such as skin-to-skin care has been challenging in many settings, particularly in Asia [16]. Because "warm chain" thermoprotective behaviors are often not practiced, health technologies have been proposed to facilitate the implementation of skin-to-skin care and other interventions [17]. One such technology purposely chosen for this study because of its innovative design and potential in resource-limited settings is a lowcost, sleeping bag-like infant warmer with a warming element designed for resource-limited environments [18]. Results from a clinical trial in Bangalore, India, suggest that the device achieves a statistically significant higher body temperature and effectively maintains body temperature compared with radiant warmers, blankets, and other methods to warm babies in hospitals with limited resources [19].

The WHO acknowledges that health technologies and medical devices are indispensable in health care delivery, but also recognizes that their affordability and appropriateness in low-income countries are still insufficient [20]. The WHO Global Initiative on Health Technologies, launched to encourage affordable innovation for resource-limited communities, found distribution challenges to be a major impediment to commercializing innovative, accessible, robust, and affordable health technologies for resourcelimited environments [21].

Resource constraints and an unstable political system substantially limit adequate distribution of appropriate health technology in Nepal's public health care sector. The aftermath of the April 2015 earthquake also added immensely to the Nepalese public health care system's already overstretched burden. Nepal's private sector has historically provided important health care capacity, but at relatively high costs to patients. In the absence of health insurance in Nepal [22], patients cover about $70 \%$ of total health costs out of pocket, totaling $3.6 \%$ of gross domestic product (GDP). While the private sector provides nearly twice the number of hospital beds of public hospitals, its profitdriven services are concentrated in the wealthy and urban areas of the country's central region and do not reach economically disadvantaged rural populations [23]. Because Nepal's disadvantaged are less able to pay out of pocket for private sector health services, they predominantly rely on public health services that now more than ever are inadequately resourced to meet demands [24].

Indeed, existing distribution channels for any health technology hardly extend beyond the capital city of Kathmandu and do not reach economically disadvantaged populations in remote rural areas. Traditionally, most public health interventions in resource-limited countries, including distribution of health technologies, substantially depend on limited public budgets or external, unsustainable grant funding.

To address the disadvantages of low-income populations that live remotely from health system structures, we developed a private sector device distribution model that takes on newborn hypothermia and ultimately newborn health in Nepal and ensures equitable access to newborn thermal protection across population income strata.

\section{Methods}

This was a qualitative, formative study to develop a potentially self-sustaining implementation and distribution model for newborn health technology independent of conventional public or philanthropic funding. We did not aim to demonstrate effectiveness or efficacy of any particular device, but rather aimed to provide a concept for implementing a thermoprotective intervention for newborns in Nepal's rural communities currently inadequately served by the public health system.

\section{Data collection}

We systematically searched key policy documents and peer-reviewed literature in standard reference databases and through expert referral to assess the regional burden of newborn hypothermia and existing approaches to address it in Nepal. We also conducted qualitative in-depth interviews with key stakeholders in urban, suburban, and rural settings in and around Kathmandu and Narayangarh, Nepal, representing the fields of newborn health and social entrepreneurship. We identified informants through expert referral. Interviews followed a semi-structured questionnaire, soliciting information and probing attitudes about newborn care and hypothermia.

Using a purposive expert sampling strategy, we sampled a total of 21 potentially information-rich experts among Nepalese and international nongovernmental organizations (NGOs) (Nepal Family Health Program, $n=2$; Mother and Infant Research Activities, $\mathrm{n}=2$; Nick Simons Institute, $n=1$; and Save the Children, Kathmandu, $\mathrm{n}=2$ ), international organizations (the United Nations Children's Fund [UNICEF], Kathmandu, $\mathrm{n}=2$ ), and social entrepreneurs (Ashoka Foundation, Nepal, $\mathrm{n}=1$ ). Further information was obtained from providers at urban hospitals (Kanti Children's Hospital, $\mathrm{n}=2$, and Patan Hospital, Kathmandu, $\mathrm{n}=2$ ), from employed and volunteer health workers in rural health posts at various distances from 
urban centers $(n=4)$, and from rural educational facilities (Balkumari College, Narayangarh, $n=3$ ). Based on respondents' preferences, we conducted interviews in English or Nepali with simultaneous translation into English and transcribed pertinent quotes in English. We did not collect data on respondents' identities and did not record any personal information. We informed all participants of the study purpose and obtained their verbal consent to participate before starting the interviews.

\section{Data analysis}

We conducted a content analysis according to Miles, Huberman, and Saldaña's approach to memoing and coding [25]. First, following a thematic analysis of key policy documents, we produced theoretical memos based on an initial interview data read to guide further data collection and iterative analysis. Then, in an initial cycle of content analysis, we manually coded responses into these categories: (i) local health care systems and their key stakeholders, (ii) health care practices and financing, and (iii) perceptions of available and needed services. To develop our theoretical model, we secondcycle coded and organized data by topic area such as health care system and newborn care, income generation, and savings groups and microfinance activities.

\section{Study setting}

Nepal is one of the world's most economically disadvantaged and least developed countries. More than 25\% of its nearly 31 million people live below the poverty line, and the estimated 2015 GDP per capita was US\$2500 in purchasing power parity (PPP), ranking 197 out of 230 countries globally [26]. After years of violent political struggle, the culturally distinct country is currently the youngest republic in the world and is transitioning from monarchy to democracy. Improvements in health have been prioritized as key to the still unfinished peacebuilding process in Nepal [27]. The country's current Gini index of 32.8 has been decreasing, which indicates an increasingly equitable society [26], but substantial inequality still exists in post-conflict Nepal.

Nepal is geographically diverse and divided into distinct ecological zones. Environmental temperatures vary in the Terai lowlands and in the hill areas between slightly below $0^{\circ}$ and $43{ }^{\circ} \mathrm{C}$ and in the mountain areas between far below freezing and $29^{\circ} \mathrm{C}$ [2].

More than 1500 deliveries are estimated to take place in Nepal daily [4]. Most deliveries occur at home (63\%), while $35 \%$ take place in a health facility (26\% in public sector health facilities, $2 \%$ in nongovernment facilities, and $7 \%$ in private facilities) [1]. Delivery in a health facility varies widely by ecological region, is twice as common in urban areas, and is strongly positively associated with mother's education and wealth quintile [1].

\section{Results}

This section presents a scoping review of the literature and of Nepal's policy documents pertaining to newborn children. It also sets forth our model for distributing thermoprotective technologies for newborns.

\section{Document and literature analysis Newborn health in the context of the Nepalese health care system}

Historically, Nepal enjoyed relative stability, though massive inequality, under a succession of monarchs until it entered into a violent struggle for democracy in the twentieth century. Since democracy was introduced in 1990, Nepal has experienced ongoing political instability. A decade of deprivation and violence during the Maoist insurgency beginning in 1996 negatively affected communities and basic health service delivery, particularly for women and children [28]. Although the Maoist revolution ended in 2006 with the declaration of Nepal as a federal democratic republic and an interim constitution came into force in 2007, the country remains politically unstable. Even before the 2015 earthquake, the postconflict Nepalese health system suffered from lack of funds, chronic shortage of human resources, corruption, and inequitable access to health care [29].

Over 15 years ago, national researchers compiled the 2001 Situation Analysis Report on newborn mortality, newborn health, and health care in the country [cited in 30]. In response, Nepal's Ministry of Health and Population (MoHP) and NGOs such as Save the Children/Saving Newborn Lives created a Newborn Working Group to help develop a national newborn health policy. At that time, Nepal was the first Asian country to make newborn survival a development priority through the Nepal Neonatal Health Strategy, issued by the MoHP in 2004. To implement the policy, the MoHP conducted a rapid assessment of neonatal health programs in 2007 and, under the leadership of the Family Health and Child Health Divisions, engaged stakeholders to develop the National Neonatal Long Term Plan 2005-2017 [30].

This approach made newborn health a national priority. Since then, all policies in Nepal, such as the national periodic health plans (9th plan, 10th plan, and interim plan) and the Nepal Health Sector Plans I (2004-2009) and II (2010-2015), recognize newborn health as a component of essential health care services in Nepal and emphasize improved access for economically disadvantaged and vulnerable groups [31]. As a result, existing policies and strategies guided by the Nepal Neonatal Health Strategy provide both a conducive environment and a framework to develop and implement newborn innovations for disadvantaged people in the country [31, 32].

Nepal has four national hospitals, four regional and subregional hospitals, eight zonal hospitals, and 65 district 
hospitals, receiving referrals from 168 primary health care centers (which have a doctor, four nurses, and a goal of 15 beds including three maternity beds). Beyond the primary health care centers are 696 health posts providing antenatal and postnatal care-some with birthing centers. The more than 3100 sub-health posts also provide antenatal and postnatal care [1].

While the Nepalese public health care system theoretically provides health care and medications free of cost, in reality the system encounters significant resource limitations. Public health expenditure in Nepal is only $2.4 \%$ of GDP, or $5.8 \%$ of government expenditure, with an annual budget of about US\$3 per capita [33]. Many urban but particularly rural populations in Nepal have no physical access to these services, cannot afford transportation costs, or lack knowledge about how to gain access. NGOs and private health care operate on a fee-forservice basis. Although several central public hospitals provide tertiary care without charge, these higher-level institutions are likewise insufficiently resourced.

Nepal's health system relies heavily on its unique cadre of community health workers, the female community health volunteers (FCHVs). Almost 50,000 FCHVs, in general one per ward covering about 50 households, have been trained to serve the health care needs of the population at the community level [34]. FCHVs, many of whom are literate, are selected from women in the community [28]. In general, FCHVs spend an average of about 5 hours a week on primary care and prevention activities such as vaccination campaigns or communitybased treatment of pneumonia and attend an average of about 16 deliveries per year [35]. Under the Nepalese MoHP's newborn care package, FCHVs are trained in basic newborn care, and national policy aims for skilled birth attendants capable of attending both mother and child to attend all births [36].

\section{The impact of significant financial barriers on safe delivery practices in Nepal}

In Nepal, most births (63\%) take place at home, and skilled attendants assist only 36\% [2]. High-risk delivery and hazardous newborn care practices at home, often rooted in traditional beliefs, remain common [37]. Even with trained birth attendants, beneficial thermoprotective practices are often neglected. Heating the birthplace, a first critical step for home birth, is not done consistently [38, 39]. Although wrapping the child and delayed bathing prevents heat loss from evaporation, most trained birth attendants simply place the baby on the floor after birth, often without drying or wrapping the baby, and many bathe the baby soon after birth [38-40].

A survey study from Nepal [41] found that the average household cost of a home delivery ranges from Nepalese rupees (NPR) 410 without a skilled birth attendant to
NPR 879 with a birth attendant (US\$5.85 to 12.56 , respectively, at a rate of NPR 70 per US\$ at the time of that study). An uncomplicated, facility-based delivery averaged fees of NPR 678 (US\$9.70), with additional charges and opportunity and transport costs adding up to a total exceeding NPR 5300 (US\$75), and a caesarean section averaged fees of NPR 11,400 (US\$160). Based on these figures, the cost of financing current practice is NPR 45 (US\$0.64) per capita. The per capita cost of universal institutional delivery is substantially larger than the cost of universal skilled birth attendance at home (NPR 400 vs. 117 , or US\$5.75 vs. 1.70, respectively) [41].

In light of the substantial household costs associated with childbirth, Nepal's government developed and implemented the Safe Delivery Incentive Program in 2006 to motivate women to seek birth attendance at health institutions. This conditional cash transfer program offered incentives ranging from NPR 1500 (US\$21.45) in the mountain regions to NPR 1000 (US\$14.30) in the hills and NPR 500 (US\$7.15) in the Terai lowlands, primarily to defray transportation costs to reach birthing facilities. Skilled birth attendants were to be paid NPR 300 (US\$4.30) per delivery [42]. While financial incentives offered directly to the targeted population in the form of conditional cash transfer programs have had success in Latin America [43-45], Nepal's Safe Delivery Incentive Program had considerable bureaucratic and communication problems [46].

\section{Low-cost interventions for resource-limited populations}

To develop a newborn thermal care strategy for Nepal, we conducted a scoping review of newborn care and dedicated newborn health technology in a global context.

More than 2.2 billion people worldwide currently live at a poverty level of less than US $\$ 2$ a day [47]. Newborn care interventions tend to be low-cost, but highly costeffective, especially when integrated into existing delivery services. Globally, a package of interventions and scale-up of existing services to nearly universal coverage in the developing world could avert up to $72 \%$ of newborn deaths, which translates into almost 3 million lives saved [48]. This would cost an additional US $\$ 4.1$ billion globally, or US\$2100 per newborn death averted, beyond the current expenditures of US $\$ 2.0$ billion for newborn survival [49]. Currently, newborn care interventions have not achieved scale or permanence globally, and local strategies are urgently required.

Implementation of culturally adapted methods of thermal care through continuous skin-to-skin contact, a key part of kangaroo mother care, is associated with a decreased infectious morbidity [50] and mortality [51] among low-birth-weight infants. However, no clear evidence shows that this strategy is sufficient to improve infant mortality outside of hospital settings, and it remains 
unavailable at scale in most resource-limited countries [51-53]. Furthermore, given various contextual barriers, implementation of skin-to-skin care has been challenging in many places, including Nepal.

To provide additional heat sources for effective thermal protection of newborns in resource-limited environments, academia and industry are developing various low-cost, low-technology newborn warming devices [18]. Both barriers to heat loss and external heat sources have been shown to be effective in reducing heat loss in infants [8]. One low-technology device, an infant warmer in a sleeping bag design incorporating a warming element, provides passive and active thermoprotection and was designed to complement or replace other available options for thermoprotection (Table 1) [47]. While the device provides a potential approach to the newborn hypothermia challenge, at present it lacks a distribution strategy and remains out of reach for most of Nepal's population.

\section{Newborn technology distribution model}

Our scoping literature review and qualitative interviews provide data to develop a distribution model for this or similar newborn technologies. Our analysis of qualitative data identified relevant market segments and distribution strategies in Nepal as follows:

\section{Economically disadvantaged rural populations}

Approximately $25 \%$ of the Nepalese population earns less than US\$1 per day and has no disposable income beyond subsistence [26]. Many women in rural Nepal are organized in mothers groups with a strong community spirit. In general, much of the income-generating activity takes place in a communal context. Due to the limitations that economically disadvantaged families have in providing thermal protection for their newborns, the greatest burden of newborn mortality attributable to hypothermia falls on economically disadvantaged rural populations and makes access to newborn interventions a priority for this segment.

\section{Economically disadvantaged urban populations}

Many economically disadvantaged rural individuals migrate to urban areas in search of work, where community ties are weaker than in rural areas. Although many economically disadvantaged urban people may not have much more disposable income than their rural counterparts, they do have better access to the public health system.

\section{High income}

High-income populations in Nepal are willing to spend significant amounts for newborn care. This population stratum may find a device dedicated specifically to newborn thermal protection a cost-effective alternative to heating the home.

Based on this market segmentation, we developed a four-pronged approach that includes local entrepreneurs to distribute the thermal protection device on a commercial basis (Fig. 1). The typical practice of distribution through businesses to private and public health care providers does not reach mothers and their infants directly. In addition, costs associated with any device make it unaffordable for most of the target population: economically disadvantaged rural and urban people. Our model, in contrast, involves social entrepreneurs and microfinance organizations to reach mothers and their newborns at the time and place of delivery, makes the device affordable to the economically most disadvantaged, and enhances the intervention's sustainability. It also provides the economically disadvantaged a previously unavailable choice in how to use their limited resources, both individually and collectively.

Table 1 Options for newborn thermal protection in resource-limited settings

\begin{tabular}{|c|c|c|c|c|}
\hline Method & Eligibility & Advantages & Risks or disadvantages & Availability \\
\hline $\begin{array}{l}\text { Skin-to-skin contact (SSC) } \\
\text { by mother or other } \\
\text { caregiver }\end{array}$ & Stable infants & $\begin{array}{l}\text { Mother can closely } \\
\text { monitor, promotes } \\
\text { bonding }\end{array}$ & $\begin{array}{l}\text { Not for life-threatening } \\
\text { conditions }\end{array}$ & $\begin{array}{l}\text { Community } \\
\text { and institutional }\end{array}$ \\
\hline $\begin{array}{l}\text { Radiant warmer or water } \\
\text { mattress }\end{array}$ & At-risk infants & $\begin{array}{l}\text { Allows observation of baby } \\
\text { Allows procedures to be } \\
\text { performed }\end{array}$ & $\begin{array}{l}\text { Hyperthermia, dehydration } \\
\text { Expensive to buy, requires } \\
\text { electricity }\end{array}$ & Institutional only \\
\hline Incubator & $\begin{array}{l}\text { At-risk infants, including } \\
\text { high-risk, low-birth- } \\
\text { weight infants }\end{array}$ & $\begin{array}{l}\text { Maintains constant temperature } \\
\text { and humidity } \\
\text { Easy provision of oxygen } \\
\text { Allows observation of } \\
\text { (naked) infant }\end{array}$ & $\begin{array}{l}\text { Hyperthermia, dehydration } \\
\text { Expensive to buy, maintain, } \\
\text { clean; requires electricity } \\
\text { Separation of mother and child }\end{array}$ & Institutional only \\
\hline Warm room & Stable infants & $\begin{array}{l}\text { No newborn equipment } \\
\text { necessary }\end{array}$ & $\begin{array}{l}\text { Hypothermia } \\
\text { Uncomfortable for caregivers }\end{array}$ & $\begin{array}{l}\text { Community } \\
\text { and institutional }\end{array}$ \\
\hline $\begin{array}{l}\text { Low-cost warming device } \\
\text { (together with SSC) }\end{array}$ & At-risk and stable infants & $\begin{array}{l}\text { Mother can closely monitor, } \\
\text { other caregiver can provide } \\
\text { SSC }\end{array}$ & $\begin{array}{l}\text { Not appropriate for life- } \\
\text { threatening conditions; more ex- } \\
\text { pensive than SSC }\end{array}$ & $\begin{array}{l}\text { Potentially community } \\
\text { and institutional }\end{array}$ \\
\hline
\end{tabular}




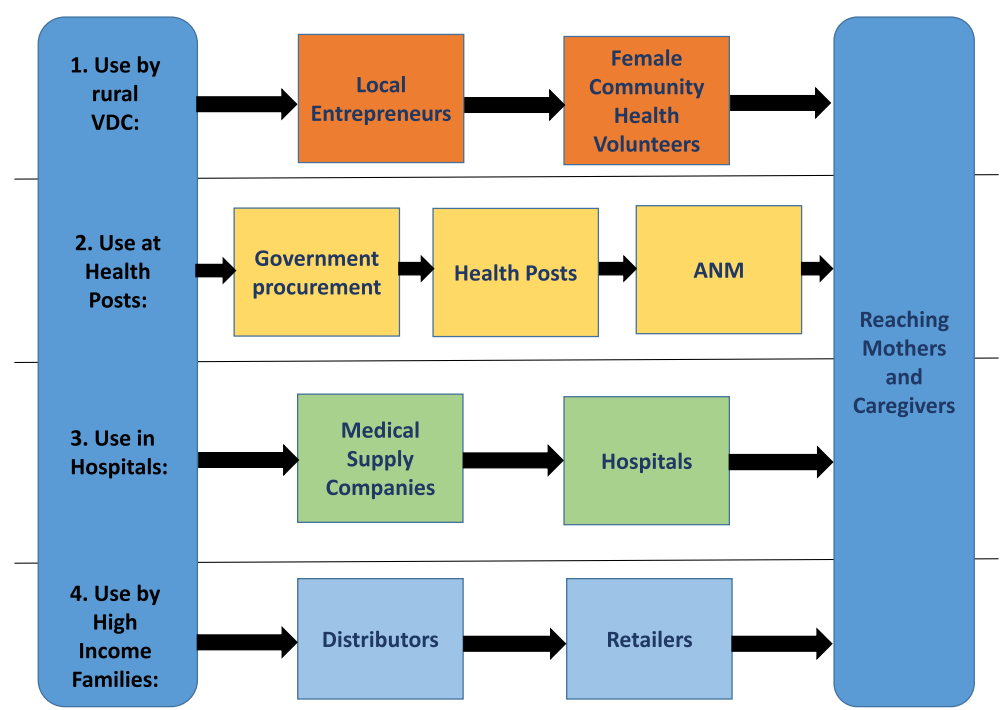

Fig. 1 Business model overview: The intervention can be launched by manufacturers or through a wholesaler (ANM, auxiliary nurse midwife; VDC, village development committees)

We explored acceptable price ranges for different target groups among key informants. Suggested retail prices vary by segment and will eventually follow market dynamics, given the expected interaction among the segments. Marketed differentially, motivated wealthy urban buyers can afford and are expected to accept higher prices than economically disadvantaged urban or rural people. As a result of a cross-subsidization scheme at the distributor level, those with more purchasing power will make the intervention affordable for the most economically disadvantaged.

\section{Economically disadvantaged rural populations at the community level}

In rural areas, about 50-120 households are grouped into wards, of which Nepal has about 35,000. In turn, wards are organized into about 3900 village development committees (VDCs). Rural VDCs represent the majority of the population and its most vulnerable families. Almost all mothers in rural villages live at subsistence level. Because individuals are too poor to pay for an intervention, our model targets mothers groups, of which about 50,000 exist nationwide, and Nepal's numerous savings and microfinance groups. These groups usually pool NPR 5-500 (currently about US\$0.05-4.70) per participant per month into a general fund. Another option is to target the 13,000 forest user groups-agricultural microcredit groups that include almost a third of Nepal's population. Even though their activities are typically not directly related to health interventions, they do generate communal income.

Our model proposes to distribute the device to local entrepreneurs. To promote his or her commercial activities, an entrepreneur typically has relationships with specific community decision makers in a given territory. By virtue of their ability to mobilize savings, microfinance organizations then purchase the device directly from an entrepreneur. In a variation of this model, a forest user group could loan or donate funds to a mothers group to obtain a device. The mothers group in turn identifies an overseer of the device in the community to ensure its use at the time and place of a delivery.

In this rural distribution strategy, nationally active FCHVs potentially play a crucial role. Under the Nepal Neonatal Health Strategy, FCHVs deliver the Community-Based Newborn Care Package, a program to prevent and manage newborn infections, hypothermia, and asphyxia, and to develop an effective system for referral of sick newborns $[54,55]$. Serving as the liaison to the entrepreneur to acquire the device; later assisting eligible mothers to allocate, use, and clean the device; and facilitating its acceptance by families, the FCHV would receive monetary compensation from the entrepreneur for her services. Thus, both the entrepreneur and the FCHV would have an incentive to distribute the device and, assuming its use is beneficial and culturally accepted, encourage its proper and sustainable distribution and use. A suggested price of NPR 3000 (currently about US\$28) would be affordable for a savings group and would cover production costs and generate income for the entrepreneur and the FCHV, under the condition that policy makers and the community accept this as appropriate.

\section{Economically disadvantaged rural people at health posts}

The government of Nepal publicly funds and provides all products and services at health posts. Although a minority of deliveries occurs at health posts, national policy 
aims to increase the proportion of institutional births. Typically, a health post with an average of two attended births per month should stock more than one device to protect the newborn until a device from the community is available for transport and use at home. Alternatively, a health post could loan the device to the mother for a deposit to ensure return of the device and possibly encourage the mother to make a follow-up visit.

The distribution of 8800 devices needed nationwide could occur through established government channels, which currently distribute other medical supplies to the health posts. A suggested price of NPR 6000 (US\$56) per device was determined as acceptable in this segment. The total cost to the government of about US $\$ 493,000$ corresponds to less than US\$0.02 per capita (about NPR 2), which we consider a low-cost proposition for potentially life-saving thermal protection of newborns.

\section{Central and district hospitals}

Like many developing countries, Nepal has an unmet need for secondary and tertiary care equipment in general and for thermal protection devices in particular. The need for incubators is neither met in better-equipped central hospitals in Kathmandu nor in district hospitals. On an institutional level, thermal protection is needed at the place of delivery, during transport to the nursery, in the nursery, and eventually at home to allow for early discharge. The newborn warming device meets these needs, with the exception of a small number of very high-risk, high-morbidity newborns requiring more specialized care.

At a suggested price of NPR 5000 (US\$46.60) per device sold to hospitals through established medical products distribution companies, hospitals can stratify their distribution based on the income level of the patient:

I. To upper-middle-income or upper-income patients, provide the device to patients' families upon discharge at the price of NPR 6000 (US\$58) with a margin of NPR 1000 (US\$9.30). Private hospitals can sell this device directly. Public hospitals may not sell medical supplies directly but can induce purchase of the device at nearby local pharmacy retail stores.

II. Rent the device out on a daily basis and for a deposit to ensure return of the device.

III.Loan the device for free to those unable to afford renting the device, also with collateral. Hospitals can make their own arrangements in this regard and may find early discharge of patients with the device beneficial, even if a deposit cannot be secured.

The potential target institutions span public district hospitals, primary health care centers, health posts, subhealth posts, and private sector hospitals, each with an estimated demand of 10-30 devices per year.

\section{Upper-middle- to high-income urban citizens}

Upper-middle- to high-income urban families with newborns have better access to newborn health care. However, even private health care facilities do not provide adequate thermal protection. Another advantage of targeting this segment is the cross-subsidization of the costs of the other channels, particularly of savings and credit groups, thus making the device more accessible to economically disadvantaged rural populations. This product would be differentiated as a high-end product, with distinct material and packaging, different color and design options, and various sizes, to justify the substantially higher retail price compared with the rural market segment. The suggested target price of NPR 7000 (US\$65) includes the marginal cost for the more elaborate production and a margin for distributors and retailers.

\section{Discussion}

We present a concept of providing access to thermoprotective newborn technology for all segments of society in Nepal. The model specifically targets rural families in Nepal through social entrepreneurs, savings groups, and microcredit organizations to implement a newborn health intervention and distribute health technology to economically disadvantaged urban and rural populations that could otherwise not afford it at the time and place of the highest hypothermia burden. Our findings intend to inform planning, implementation, and dissemination of newborn health care interventions and health technology in the context of poverty and limited health infrastructure.

Appropriate technology for newborn care in primary and secondary health care facilities might be an important adjunct to community-based management strategies [50]. Traditionally, private sector providers have played an important role in fostering maternal and child health interventions, but were not necessarily structured for scale or permanence. The public sector, however, could potentially provide large-scale interventions, but has been weak with regard to efficacy and efficiency. In a changing global health landscape, both sectors must contribute to address the global burden of disease that falls disproportionally on low-income populations [56].

Founded on viable, profitable enterprises, business methods tailored to the economically disadvantaged could link scale and sustainability with efficacy and efficiency. Few markets are as highly motivated and attuned to innovative commodities and technologies as expectant mothers and their families are. Given that background, the business sector, with its power to innovate and ability to create sustainable models for constructing, deploying, and delivering products, might have a unique capacity to provide appropriate tools and technologies even in the remotest areas [57]. 
In the past 5 years, the government of Nepal introduced several newborn health programs, including the Community-Based Newborn Care Package, which has a birth-preparedness package, chlorhexidine application to a newborn's umbilical cord to prevent infections, and the newborn vitamin A supplementation program to reduce morbidity and mortality during early infancy. These pilot programs have not been fully implemented or scaled up [58]. The 2015 earthquake, which added an immense burden to Nepal's already strained public health care system, widened the delivery gap for economically disadvantaged rural and urban populations. Social enterprises and social marketing, the application of commercial marketing concepts and techniques to promote voluntary behavior change [59], might provide a missing link to deliver essential public health services or health technology to populations with limited income.

Selling a device to mothers groups or community income-generating groups that in turn sell or lend it to individual mothers might seem absurd given the poverty of most mothers in Nepal. However, experiences from various savings-led microfinance enterprises in South America and Southeast Asia suggest that profitable enterprises specializing in serving the low-income sector might have a measurable impact on the health of the economically disadvantaged [60]. By improving the health and thus the productive capacity of these people to a meaningful extent, commercial ventures addressing health might strengthen the ability of low-income populations to maximize their earnings and increase their assets, thereby improving quality of life for current and future generations [61]. Private sector organizations have developed several innovations in health service delivery with the potential to better serve the health needs of economically disadvantaged populations [62]. If for-profit health care proves profitable, these investments might be a step for developing countries toward escaping dependency on foreign aid [63].

Notably, our theoretical model does not exclude the public sector and its advantages in advancing health technology. For institutions and in urban areas, selling the device-marketed and priced differentially to health care institutions and to urban high-income users-might help to target it to low-income families through cross-subsidization.

In rural areas, this health technology delivery model is based on the services of an existing network of trained FHCVs who already have access to mothers and can thus provide effective thermal protection for infants, when and where these births occur. Given that national policy supports institutional births, the role of FHCVs in deliveries is controversial. However, FCHVs-who are trained in antenatal counseling and providing postnatal visits-have achieved notable improvements in household practices and service utilization [64]. Trained birth attendants in Nepal practice beneficial newborn interventions but are reported to neglect thermal care [40], a situation that our model specifically seeks to address. In distributing a device, the potential also exists for the FHCV to relay important educational messages to mothers about protecting their newborns from hypothermia. While limited literature exists on the quality of care they provide, FCHVs with higher education levels (secondary and above) and those who are active in areas where research programs and NGOs are already active have been found to perform satisfactorily [65].

This distribution model could also be aligned with or integrated into other, currently existing relevant activities, such as newborn resuscitation programs [66]. Participatory community-based interventions in women's groups have had beneficial effects on home care, health care-seeking behavior, and newborn mortality outcomes [67]. Health technology can best innovate in the context of innovative approaches across the health systems building blocks, such as novel approaches to community ownership and participation, but also innovations regarding the health workforce and health financing [68].

Given the failure of conditional cash transfer programs in Nepal to increase institutional deliveries, FCHVs and other skilled or traditional birth attendants might bridge the gap to safe delivery practices where most births presently take place-at home. Providing financial incentives to volunteers, as our model proposes, does not necessarily conflict with volunteerism. Financial and non-financial incentives, designed in their given context to enhance intrinsic motivation, have been found essential to the maintenance and sustainability of community-based programs and proven to increase workers' retention [69]. While microcredit groups may not always reach the poorest of the communities [70], newborn and maternal health aspects are meaningful microfinance activities, because mothers will take ownership. At the same time, our model integrates several innovations shown to improve the availability and affordability of health care for the economically disadvantaged, such as cross-subsidies, high-volume and low-cost models, and technical simplifications that focus on a circumscriptive clinical issue [71].

\section{Limitations}

This study developed a distribution model for newborn health technology. Future studies will have to test its implementation and whether the device and the implementation of this model reduce newborn mortality due to hypothermia. Circumstances have clearly changed since the devastating 2015 earthquake, with income generation, infrastructure repair, and food security gaining prominence. Nevertheless, newborn survival remains a top priority in Nepal, providing strong support for the model's continuing applicability. 


\section{Conclusions}

Newborn hypothermia is a major risk factor for newborn survival in Nepal, and resource limitations and distribution challenges are major impediments for most of Nepal's population to access health technologies addressing this problem. Market-oriented incentives for an existing network of female community health volunteers and social entrepreneurs in Nepal might deliver newborn health interventions to economically disadvantaged mothers at the time and place of birth, while triggering demand for appropriate health technology and related health promotion behaviors.

Harnessing market forces could promote public health by raising awareness for newborn challenges such as newborn hypothermia. Based on commercial methods, this model's implementation could potentially provide low-cost, low-technology thermal protection for newborns in Nepal in a timely manner, targeting specifically the poorest families. Application and evaluation of this model will further contribute to our understanding whether market mechanisms can promote the delivery of public health interventions to reach vulnerable populations effectively and efficiently.

Business methods tailored to economically disadvantaged populations could make interventions available at scale and make them sustainable, independent of external grant funding. Targeting low-income populations through local social entrepreneurship might bridge a gap between health service and health technology delivery and finally reduce disease burden. Market approaches to promoting public health have been somewhat neglected, especially for economically disadvantaged and vulnerable populations, and deserve greater attention in Nepal and other settings with limited public health service delivery capacity.

\section{Abbreviations \\ ANM: auxiliary nurse midwife; DHS: Demographic and Health Surveys; FCHVs: female community health volunteers; GDP: gross domestic product; MoHP: Nepal's Ministry of Health and Population; NGOs: nongovernmental organizations; NPR: Nepalese rupees; PPP: purchasing power parity; SSC: skin- to-skin contact; UNICEF: United Nations Children's Fund; US\$: United States of America dollar; VDCs: village development committees; WHO: World Health Organization}

\section{Acknowledgments \\ This study was part of Project Antares, a joint endeavor of the Harvard Chan School of Public Health and the Harvard Business School. We thank the Antares team for their valued feedback. We are profoundly grateful to Principal Chiranjibi Shrestha (Balkumari College, Narayangarh), Anil Chitrakar, and Kushal Joshi for their support and to Reema Shresta for her help with interpretations. We gratefully acknowledge Larry Rosenberg for his critical review of an earlier version of the manuscript.}

\section{Funding}

This study was supported by funds from Roslyn Payne and a grant from the Brinson Foundation.

\section{Availability of data and materials}

All transcribed text data and field notes will be made available by the corresponding author to interested third parties upon request.

\section{Authors' contributions}

$\mathrm{KL}, \mathrm{RD}, \mathrm{AT}, \mathrm{SA}, \mathrm{MC}$, and $\mathrm{DB}$ conceived this study. $\mathrm{MC}$ and $\mathrm{DB}$ secured the funding for this study. KL, RD, AT, and SA collected and analyzed the data, with important intellectual input from $M C$ and $D B . K L, R D, A T$, and $S A$ drafted the manuscript, for which MC and DB provided important intellectual contributions. All authors read and approved the final manuscript.

\section{Ethics approval and consent to participate}

This study was determined nonhuman subject research by the Harvard University internal review board. Consent for publication was not required.

\section{Consent for publication}

Not applicable. All data were anonymous and not identifiable.

\section{Competing interests}

The authors declare that they have no competing interests. Abeezer Tapia worked with Embrace Global after contributing to this study, which had no influence on this study.

\section{Publisher's Note}

Springer Nature remains neutral with regard to jurisdictional claims in published maps and institutional affiliations.

\section{Author details}

${ }^{1}$ Department of Global Health and Population, Harvard T.H. Chan School of Public Health, 677 Huntington Avenue, Boston, MA 02115, USA. ${ }^{2}$ Boston Medical Center, 801 Massachusetts Avenue, Boston, MA 02118, USA. ${ }^{3}$ Harvard Business School, Soldiers Field, Boston, MA 02163, USA

Received: 22 August 2016 Accepted: 24 November 2017

Published online: 19 December 2017

\section{References}

1. Demographic and Health Survey Nepal 2011. accessed online at https:// dhsprogram.com/pubs/pdf/FR257/FR257\%5B13April2012\%5D.pdf.

2. Demographic and Health Survey Nepal 2006. MEASURE DHS project 2007. accessed online at http://dhsprogram.com/pubs/pdf/fr191/fr191.pdf

3. Black RE, Cousens S, Johnson HL, Lawn JE, Rudan I, Bassani DG, Jha P, Campbell H, Walker CF, Cibulskis R, et al. Global, regional, and national causes of child mortality in 2008: a systematic analysis. Lancet. 2010; 375(9730):1969-87.

4. Oza S, Cousens SN, Lawn JE. Estimation of daily risk of neonatal death, including the day of birth, in 186 countries in 2013: a vital-registration and modelling-based study. Lancet Glob Health. 2014;2(11):e635-44.

5. WHO. Thermal protection of the newborn: a practical guide. Geneva: Maternal and Newborn Health/ Safe Motherhood Unit, Division of Reproductive Health, World Health Organization; 1997.

6. Lunze K, Bloom DE, Jamison DT, Hamer DH. The global burden of neonatal hypothermia: systematic review of a major challenge for newborn survival. BMC Med. 2013;11:24. doi:10.1186/1741-7015-11-24.

7. Mullany LC, Katz J, Khatry SK, LeClerq SC, Darmstadt GL, Tielsch JM. Risk of mortality associated with neonatal hypothermia in southern Nepal. Arch Pediatr Adolesc Med. 2010;164(7):650-6.

8. Lunze K, Hamer DH. Thermal protection of the newborn in resource-limited environments. J Perinatol. 2012;32(5):317-24.

9. Lawn JE, Cousens S, Zupan J. 4 million neonatal deaths: when? Where? Why? Lancet. 2005;365(9462):891-900.

10. Johanson RB, Spencer SA, Rolfe P, Jones P, Malla DS. Effect of post-delivery care on neonatal body temperature. Acta Paediatr. 1990;81(11):859-63.

11. Johanson RB, Malla DS, Tuladhar C, Amatya M, Spencer SA, Rolfe P. A survey of technology and temperature control on a neonatal unit in Kathmandu, Nepal. J Trop Pediatr. 1993;39(1):4-10.

12. Manandhar N, Ellis M, Manandhar DS, Morley D, de L Costello AM. Liquid crystal thermometry for the detection of neonatal hypothermia in Nepal. Trop Pediatr. 1998;44(1):15-7

13. Ellis M, Manandhar N, Shakya U, Manandhar DS, Fawdry A, Costello AM. Postnatal hypothermia and cold stress among newborn infants in Nepal monitored by continuous ambulatory recording. Arch Dis Child Fetal Neonatal Ed. 1996;75(1):F42-5. 
14. Mullany LC, Katz J, Khatry SK, Leclerq SC, Darmstadt GL, Tielsch JM. Incidence and seasonality of hypothermia among newborns in southern Nepal. Arch Pediatr Adolesc Med. 2010;164(1):71-7.

15. WHO. Managing newborn problems: a guide for doctors, nurses, and midwives. Geneva: Integrated Management of Pregnancy and Childbirth, World Health Organization; 2003.

16. Dickson KE, Simen-Kapeu A, Kinney MV, Huicho L, Vesel L, Lackritz E, de Graft Johnson J, von Xylander S, Rafique N, Sylla M, et al. Every newborn: health-systems bottlenecks and strategies to accelerate scale-up in countries. Lancet. 2014;384(9941):438-54.

17. Wirth M, Thairu L, Lunze K. Low-cost technologies that can save the lives of newborns: designing promising innovations for developing countries. Global Health and Diplomacy. 2012;2(2):5.

18. Thairu L, Wirth M, Lunze K. Innovative newborn health technology for resource-limited environments. Tropical Med Int Health. 2013;18(1):117-28.

19. Bhat SR, Meng NF, Kumar K, Nagesh KN, Kawale A, Bhutani VK. Keeping babies warm: a non-inferiority trial of a conductive thermal mattress. Arch Dis Child Fetal Neonatal Ed. 2015;100(4):F309-12.

20. World Health Assembly: Resolution WHA60.29. Health technologies. In: Sixtieth World Health Assembly, Geneva, 23 May 2007, accessed online at http://www.who.int/medical_devices/resolution_wha60_29-en1.pdf.

21. WHO: Innovative technologies that address global health concerns: outcome of the call. 2010, accessed online at http://whqlibdoc.who.int/hq/ 2010/WHO_HSS_EHT_DIM_10.12_eng.pdf.

22. Jha N, Karki P, Das BP, Chapagain N. Social health insurance: knowledge-do gap in eastern Nepal. Kathmandu Univ Med J (KUMJ). 2007:5(2):268-72.

23. RTI International: Overview of public-private mix in health care service delivery in Nepal. accessed online at https://www.rti.org/sites/default/files/ resources/42 nepal_overviewpublicprivate.pdf.

24. Nepal Ministry of Health: Nepal Health Sector Implementation Plan 2004-2009. accessed online at http://dohs.gov.np/wp-content/uploads/ 2014/04/NHSP_IP.pdf.

25. Miles MB, Huberman AM, and Saldaña J: Qualitative data analysis. SAGE Publications. Thousand Oaks, CA. ISBN 978-1452257877. 2014.

26. CIA: The World Factbook: Nepal. 2016, accessed online at https://www.cia. gov/library/publications/the-world-factbook/geos/np.html.

27. Tsai TC. Public health and peace building in Nepal. Lancet. 2009;374(9689):515-6.

28. Nepal Ministry of Local Development: Improving lives for children and women in Nepal. Decentralized Action for Children and Women (DACAW) Local Body Support Section, Governance Coordination Division, Ministry of Local Development; Shree Mahal, Pulchowk; Kathmandu, Nepal. 2007, accessed online at http://unicef.org.np/uploads/files/615489217534939116final-dacaw-brochure.pdf.

29. Sharma SP. Politics and corruption mar health care in Nepal. Lancet. 2010; 375(9731):2063-4.

30. Save the Children: Newborn health and programs in Nepal. A rapid assessment of newborn health in Nepal conducted by the Department of Health Services. accessed online at http://www.healthynewbornnetwork.org/ sites/default/files/resources/Nepal_Newborn_Assessement-2007.pdf.

31. Paudel D, Shrestha IB, Siebeck M, Rehfuess EA. Neonatal health in Nepal: analysis of absolute and relative inequalities and impact of current efforts to reduce neonatal mortality. BMC Public Health. 2014;13:1239. doi:10.1186/1471-2458-13-1239.

32. Smith SL, Neupane S. Factors in health initiative success: learning from Nepal's newborn survival initiative. Soc Sci Med. 2011;72(4):568-75.

33. WHO 2017. Global Health Expenditure Database. Accessed online at http:// apps.who.int/nha/database.

34. Schwarz D, Sharma R, Bashyal C, Schwarz R, Baruwal A, Karelas G, Basnet B, Khadka N, Brady J, Silver Z, et al. Strengthening Nepal's female community health volunteer network: a qualitative study of experiences at two years. BMC Health Serv Res. 2014;14:473. doi:10. 1186/1472-6963-14-473

35. Suvedi BK. Nepal's newborn health strategy: the way forward to achieve MDG-4. Family Health Division, Nepal Ministry of Health \& Population, Kathmandu, Nepal 2008.

36. Nepal Ministry of Health. National Neonatal Health Strategy. Kathmandu: Family Health Division, Ministry of Health, Government of Nepal; 2004.

37. Gurung G. Practices on immediate care of newborn in the communities of Kailali district. Nepal Med Coll J. 2008;10(1):41-4.
38. Sreeramareddy CT, Joshi HS, Sreekumaran BV, Giri S, Chuni N. Home delivery and newborn care practices among urban women in western Nepal: a questionnaire survey. BMC Pregnancy Childbirth. 2006;6:27.

39. Osrin D, Tumbahangphe KM, Shrestha D, Mesko N, Shrestha BP, Manandhar MK, Standing H, Manandhar DS, Costello AM. Cross sectional, community based study of care of newborn infants in Nepal. BMJ. 2002;325(7372):1063.

40. Falle TY, Mullany LC, Thatte N, Khatry SK, LeClerq SC, Darmstadt GL, Katz J, Tielsch JM. Potential role of traditional birth attendants in neonatal healthcare in rural southern Nepal. J Health Popul Nutr. 2009;27(1):53-61.

41. Borghi J, Ensor T, Neupane BD, Tiwari S. Financial implications of skilled attendance at delivery in Nepal. Tropical Med Int Health. 2006;11(2):228-37.

42. Ensor T, Clapham S, Prasai DP. What drives health policy formulation: insights from the Nepal maternity incentive scheme? Health Policy. 2009:90(2-3):247-53.

43. Fernald LC, Gertler PJ, Neufeld LM. Role of cash in conditional cash transfer programmes for child health, growth, and development: an analysis of Mexico's oportunidades. Lancet. 2008;371(9615):828-37.

44. Lagarde M, Haines A, Palmer N. Conditional cash transfers for improving uptake of health interventions in low- and middle-income countries: a systematic review. JAMA. 2007:298(16):1900-10.

45. Morris SS, Flores R, Olinto P, Medina JM. Monetary incentives in primary health care and effects on use and coverage of preventive health care interventions in rural Honduras: cluster randomised trial. Lancet. 2004; 364(9450):2030-7.

46. Powell-Jackson T, Morrison J, Tiwari S, Neupane BD, Costello AM. The experiences of districts in implementing a national incentive programme to promote safe delivery in Nepal. BMC Health Serv Res. 2009;9:97. doi:10.1186/1472-6963-9-97.

47. Embrace: Embrace Global_-an infant thermoregulator designed for extreme affordability. 2016, accessed online at http://embraceglobal.org.

48. Darmstadt GL, Bhutta ZA, Cousens S, Adam T, Walker N, de Bernis L. Evidence-based, cost-effective interventions: how many newborn babies can we save? Lancet. 2005:365(9463):977-88.

49. Martines J, Paul VK, Bhutta ZA, Koblinsky M, Soucat A, Walker N, Bahl R, Fogstad H, Costello A. Neonatal survival: a call for action. Lancet. 2005: 365(9465):1189-97.

50. Bhutta ZA, Darmstadt GL, Hasan BS, Haws RA. Community-based interventions for improving perinatal and neonatal health outcomes in developing countries: a review of the evidence. Pediatrics. 2005;115(2 Suppl):519-617.

51. Lawn JE, Mwansa-Kambafwile J, Horta BL, Barros FC, Cousens S. "Kangaroo mother care" to prevent neonatal deaths due to preterm birth complications. Int J Epidemiol. 2010;39(Suppl 1):i144-54.

52. Conde-Agudelo A, Diaz-Rossello JL, and Belizan JM: Kangaroo mother care to reduce morbidity and mortality in low birthweight infants. Cochrane Database Syst Rev 2003(2):CD002771; update in: Cochrane Database Syst Rev. 2011:(3):CD002771.

53. Oza S, Cousens SN, Lawn JE. Estimation of daily risk of neonatal death, including the day of birth, in 186 countries in 2013: a vital-registration and modelling-based study. Lancet Glob Health. 2015;2(11):e635-44.

54. Pradhan YV, Upreti SR, Pratap KCN, CA K, Khadka N, Syed U, Kinney MV, Adhikari RK, Shrestha PR, Thapa K, et al. Newborn survival in Nepal: a decade of change and future implications. Health Policy Plan. 2012;27(Suppl 3):iii57-71.

55. Pradhan X, Upreti SR, Kc NP, Thapa K, Shrestha PR, Shedain PR, Dhakwa JR, Aryal DR, Aryal S, Paudel DC, et al. Fitting community based newborn care package into the health systems of Nepal. J Nepal Health Res Counc. 2011; 9(2):119-28

56. Hanson K, Gilson L, Goodman C, Mills A, Smith R, Feachem R, Feachem NS, Koehlmoos TP, Kinlaw $H$. Is private health care the answer to the health problems of the world's poor? PLoS Med. 2008:5(11):e233.

57. Pacific Health Summit: The business case for maternal and newborn health. 2010, accessed at http://www.nbr.org/downloads/pdfs/CHA/PHS_2011_ TheBusinessCaseforMNH.pdf.

58. Ban B, Tuladhar S, Pant S, Suvedi BK. Review of health and health service improvements in Nepal. J Nepal Health Res Counc. 2012;10(21):76-81.

59. Grier S, Bryant CA. Social marketing in public health. Annu Rev Public Health. 2005:26:319-39.

60. Ashe J. A symposium on savings-led microfinance and the rural poor. Journal of Microfinance. 2002:4(2):9.

61. Patouillard E, Goodman CA, Hanson KG, Mills AJ. Can working with the private for-profit sector improve utilization of quality health services by 
the poor? A systematic review of the literature. Int J Equity Health. 2007;6:17.

62. Bhattacharyya O, Khor S, McGahan A, Dunne D, Daar AS, Singer PA. Innovative health service delivery models in low and middle income countries-what can we learn from the private sector? Health Res Policy Syst. 2010;8:24. doi:10.1186/1478-4505-8-24.

63. Garrett L. The challenge of global health. Foreign Affairs. 2007;86(1):16-38.

64. Hodgins S, McPherson R, Suvedi BK, Shrestha RB, Silwal RC, Ban B, Neupane S, Baqui AH. Testing a scalable community-based approach to improve maternal and neonatal health in rural Nepal. J Perinatol. 2010;30(6):388-95. doi:10.1038/ jp.2009.181.

65. Acharya D, Singh JK, Adhikari S, Jain V. Association between sociodemographic characteristics of female community health volunteers and their knowledge and performance on maternal and child health services in rural Nepal. J Multidiscip Healthc. 2016;9:111-20. doi:10.2147/ JMDH.S98700. eCollection 2016.

66. Wrammert J, Zetterlund C, Kc A, Ewald U, Målqvist M. Resuscitation practices of low and normal birth weight infants in Nepal: an observational study using video camera recordings. Glob Health Action. 2017;10(1):1322372. doi:10.1080/ 16549716.2017 .1322372

67. Manandhar DS, Osrin D, Shrestha BP, Mesko N, Morrison J, Tumbahangphe KM, Tamang S, Thapa S, Shrestha D, Thapa B, et al. Effect of a participatory intervention with women's groups on birth outcomes in Nepal: clusterrandomised controlled trial. Lancet. 2004;364(9438):970-9.

68. Lunze K, Higgins-Steele A, Simen-Kapeu A, Vesel L, Kim J, Dickson K. Innovative approaches for improving maternal and newborn health-a landscape analysis. BMC Pregnancy Childbirth. 2015;15:337.

69. Willis-Shattuck M, Bidwell P, Thomas S, Wyness L, Blaauw D, Ditlopo P. Motivation and retention of health workers in developing countries: a systematic review. BMC Health Serv Res. 2008;8:247.

70. Center for Microfinance: Microfinance summit Nepal 2010, Kathmandu declaration. Kathmandu, Nepal, 2010, accessed online at http://www. nepalmicrofinancesummit.org/20160913/downloads/mfs2010declaration.pdf.

71. Lunze K, Hamer DH. The global challenges of improving newborn survival in the community. J Public Health Emerg 2017;1:87. doi:10.21037/jphe.2017. 11.04

\section{Submit your next manuscript to BioMed Central and we will help you at every step:}

- We accept pre-submission inquiries

- Our selector tool helps you to find the most relevant journal

- We provide round the clock customer support

- Convenient online submission

- Thorough peer review

- Inclusion in PubMed and all major indexing services

- Maximum visibility for your research

Submit your manuscript at www.biomedcentral.com/submit

) Biomed Central 